\title{
Del XIX al XXI: miradas sobre lo clásico a través del estudio del Friso del Templo de Apolo Epikourios en Bassai
}

\section{From 19th to 21st century: a gaze on classics through a study of the Frieze of the Temple of Apollo Epikourios at Bassai}

\author{
JoRGE EGEA \\ Facultad de Bellas Artes. Universidad de Barcelona. \\ jorgeegea@ub.edu
}

Recibido: 18 de octubre de 2012

Aprobado: 23 de marzo de 2013

\section{Resumen}

El arte del siglo XIX creó un vínculo con el arte clásico que ha influido de una manera notable en nuestra manera de entender y relacionarnos con la antigüedad. El re-descubrimiento del templo de Apolo Epikourios en Bassai en 1811, en el teritorio de la Arcadia, es un caso paradigmático. Su friso, conservado en Londres, en el Museo Británico, ha sido objeto de nuestro estudio para analizar tres momentos históricos diferentes que confluyen en este friso: el siglo V a.C, época de la realización del friso, el siglo XIX, momento de la excavación arqueológica, y el siglo XXI, momento en que estudiamos y proponemos nuevas aproximaciones a dicho friso.

La originalidad de este friso permitió desde su descubrimiento repensar lo clásico y, del mismo modo, nos ha permitido mirar este legado artístico desde la contemporaneidad.

Desde el grupo de Investigación Gracmon del Departamento de Historia del Arte (UB), a través del proyecto El Otro siglo XIX (ref. HAR2010-16328/HIST-ARTE) estamos estudiando esta influencia, en el vértice que une la Arqueología, la Historiografía y las Bellas Artes como herramientas útiles para estudiar el arte del pasado.

Palabras Clave: escultura, arte griego, clásico, interpretación artística, museo.

Egea, J. (2013): Del XIX al XXI: miradas sobre lo clásico a través del estudio del Friso del Templo de Apolo Epikourios en Bassai. Arte, Individuo y Sociedad, 25(3) 476-493

\begin{abstract}
19th century art created a link with Classical art that has had a remarkable influence on the way we understand and relate to antiquity. The re-discovery of the temple of Apollo at Bassai Epikourios in 1811, in the territory of Arcadia, is a case in point. Its frieze, preserved in London, in the British Museum, has been the subject of our study to analyze three different historical moments that shaped this frieze: the 5th century BC, the time of the completion of the frieze, the 19th century, the time of excavation archaeological, and the 21 st century, when we study and propose new approaches to the frieze.

Since its discovery, the originality of this frieze allowed rethink the classical and in the same way it has allowed us to look at this artistic legacy from the contemporary.

From the Gracmon research group at the Departament of Art History), through the project El Otro siglo XIX (ref. HAR2010-16328/HIST) we are studying this influence that joins Archeology, Historiography and Fine Arts as usefull tools to review the art of the past.
\end{abstract}

Key Words: sculpture, greek art, classics, artistic interpretation, museum. 
Egea, J. (2013): From 19th to 21st century: a gaze on classics through a study of the Frieze of the Temple of Apollo Epikourios at Bassai. Arte, Individuo y Sociedad, 25(3) 476-493

Sumario: 1. Introducción, 2. La originalidad clásica del templo de Bassai, 3. Aproximación a la imagen clásica del friso, 4. Las interpretaciones de Bassai en la arquitectura británica del ss. XIX-XX. 5. Interpretar la imagen clásica: una metodología experimental de la escultura a la fotografía, 6. La reincorporación: una propuesta contemporánea de interpretación, 7. Conclusiones. Referencias.

\section{Introducción}

La cultura dieciochesca había influido de manera relevante en el interés arqueológico, artístico y formativo de la antigüedad. Sin esta cultura propia del Siglo de las Luces o Enlightment, la fuerza de lo clásico para la formación de las clases acomodadas no habría tenido un lugar tan notorio.

De Londres partieron muchos jóvenes de la clase dirigente para formarse en el mundo antiguo antes de su vuelta a la vida civil en la metrópolis. Se trataba de grupos hetrogéneos, algunos de los cuales habían recibido también formación en las artes del dibujo o de la arquitectura, otros se convertirían en pioneros de la arqueología moderna.

En la mente de los ilustrados dilettanti que re-descubrieron el templo de Bassai, estaban frescas las palabras de Winckelman y su particular vision del arte grecorromano, que podemos ver recogidas en las Reflections on the imitation of Greek Works in Painting and Sculpture (1755). Winckelman ejerció desde Roma una de las mayores influencias en los jóvenes de una clase privilegiada que emprendían el Gran Tour, como un momento definitorio para completar su formación y entender y recibir in situ, el legado del pasado. Roma y el círculo de Winckelman, eran una parada obligada de este periplo.

La experiencia del Grand Tour tuvo en inglaterra una especial connotación, y el encuentro de estos especiales viajeros con la escultura clásica, con los talleres de Canova y Thorvaldsen en Roma, convertían a la escultura en un "elemento esencial y central" (Baker, 2000, P. 70).

Nada mejor que las ruinas romanas para descubrir la noble simplicidad y la calmada grandeza de la meta inalcanzable de una edad de oro de la Humanidad: el arte clásico.

Un grupo formado por los arquitectos Ch. R. Cockerell, J. Foster y K. Haller von Hallerstein, dibujantes y amantes de la cultura clásica como, J. Linkh, O. Magnus von Stackelberg y P. O. Brondsted, y el cónsul austríaco en Grecia, G. C. Gropius, realizaron su viaje de Gran Bretaña a Italia, y de Italia a Grecia. Llegaron a Bassai en $1811 \mathrm{y}$, descubriendo el templo descrito por Plinio, realizaron distintos trabajos de excavación. Embarcaron el friso íntegro esculpido en mármol, así como algunos elementos arquitectónicos que consideraron relevantes, y entregaron esta obra directamente al Museo Británico, donde se conserva hasta hoy desde 1815 (Fig.1). 


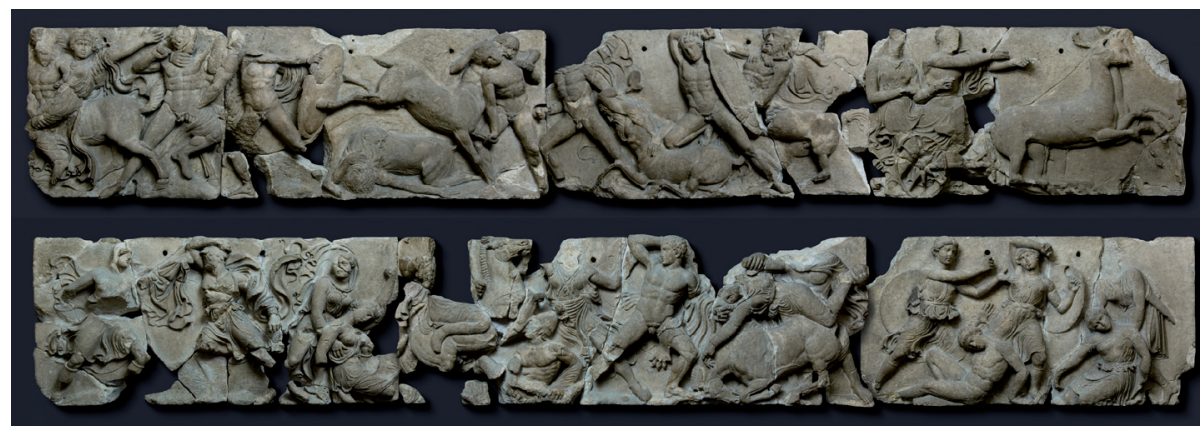

Figura 1. Lados Norte y Sur del Friso de Apolo Epikoutios. Fotografía del autor.

Dentro de nuestra investigación hemos desarrollado un estudio titulado Et in Arcadia... dirigiendo nuestra atención a este momento del pasado, pero también desde una nueva interpretación en contemporánea. Dicho estudio ha sido el fruto del trabajo realizado in situ en la sala XVI del Museo Británico entre los años 2009-2011, poniendo de relieve este diálogo transversal que relaciona tres momentos históricos: el pasado clásico del siglo V a. C., el siglo XIX y el presente. Su objetivo principal ha sido la lectura del legado clásico que se deriva del descubrimiento de este friso, analizar su influencia en la arquitectura neoclásica y, utilizando la potencialidad de las Bellas Artes para revitalizar el arte clásico, crear nuevas obras como respuesta a este diálogo entre pasado y presente.

\section{La originalidad clásica del templo de Bassai}

El templo de Apolo en Bassai es un ejemplo único en la creación arquitectónica del final del s. V a. C. En él podemos ver cómo se manifiesta la capacidad de los artistas griegos para conectar con una esencia del arte que es atemporal, que supera los condicionantes estilísticos y que sirve de ejemplo ideal para establecer la búsqueda de este diálogo con la antigüedad clásica.

Por este motivo podemos hablar de una aparente contradicción entre los términos original y clásico. Gracias a esta originalidad de Bassai hemos podido rescatar múltiples aspectos sobre el propio concepto de lo clásico.

En este mismo sentido, el templo de Bassai fue elegido específicamente por Mary Beard y John Henderson para un breve ensayo sobre qué es lo clásico, en una publicación que se ha convertido en libro de referencia en el ámbito anglosajón (Beard, Henderson, 1995). Igualmente, Bassai es el punto de partida para explicar cómo lo clásico es capaz de romper su propio molde, tal y como explica el profesor Robin Osborne (Osborne, 1998).

Destacamos aquí algunos de estos aspectos. Quizás el más llamativo sea la propia autoría. El diseño del templo está atribuido al arquitecto Ictinos, autor del Partenón, quien en torno al 420 a. C., (Pausanias, Descripción de Grecia, L. VIII, § 41, 7-9) se dedicaría a la construcción de este templo. Casi con total seguridad Ictinos aceptó este encargo tras la plaga que asoló Atenas, arriesgándose a trabajar en un territorio inhóspito que, lejos del mito de la Arcadia Feliz estaba poblado por mercenarios y 
castas militares, aliados políticos de la metrópolis ateniense. Esta alianza políticomilitar sería el fundamento para la realización de este templo de advocación guerrera (Cardete, 2010), así como para la presencia de un arquitecto ateniense en el Peloponeso.

Otro aspecto que caracteriza a Bassai es la orientación norte-sur. Supone un cambio importante ya que el eje este-oeste es el característico de los templos griegos. Esta orientación lleva consigo una percepción simbólica del espacio, sin duda relacionada con el propio dios Apolo, que en sí mismo representa la luz y, específicamente la luz solar. Esta advocación encuentra su plenitud en el eje norte-sur. En el tránsito normal de los fieles, el visitante entra al templo desde la puerta situada al norte y se dirige hacia la estatua de Apolo, que muy probablemente estuvo situada en el ádyton, al sur, y correspondería a una estatua clásica, como versión modernizada que sustituía a un antiguo xoanon de madera, siempre siguiendo la versión de Plinio.

Plásticamente, el propio templo es un nuevo espacio de experimentación creado por Ictinos, quien realiza una entrada lateral de luz en dicho ádyton, con el fin de iluminar la estatua del dios Apolo, utilizando por primera vez en la historia del arte el capitel corintio tallado en piedra, tal y como lo conocemos hoy en día.

El uso del capitel corintio no debe pasar desapercibido, pues nos recuerda cuán parcial puede ser el conocimiento de la Historia del Arte y cómo algunas anécdotas pueden hacer cambiar el conocimiento de la misma. Si seguimos los datos aportados en los diarios de los descubridores de Bassai, éste habría sido el primer caso descrito en la historia del uso de capitel corintio en piedra. Ictinos era un innovador y sus edificios estuvieron llenos de invenciones donde afloraba el ingenio y la sofisticación del arte griego clásico.

Los dibujos que se conservan en la biblioteca del Department of Greek and Roman Antiquities del Museo Británico realizados por John Foster y Haller von Hallerstein, demuestran que este primer capitel existió. Sin embargo, por un problema logístico, el capitel no se embarcó en el primer traslado del friso del templo, realizado desde el puerto de Zakynthos hacia Londres en 1814 y, desgraciadamente, había ya desparecido cuando, en una segundo expedición, volvieron para buscarlo.

Dinsmoor atribuye este primer capitel a Calímaco, siguiendo las explicaciones de Vitrubio, quien cuenta en su Tratado la leyenda por la cual Calímaco se inspira en un grupo de hojas de acanto que adornan el pedestal de una tumba. Por tanto es posible pensar en la colaboración de este artista en la transformación en piedra de la precedente forma en bronce del capitel corintio:

As the earliest Greek Corinthian capitals all suggest a metallic origin and as Callimachus is known to have worked both in bronze and in marble, it may be conjectured that he reproduced in marble a type of capital which was copied from one in bronze.

(Dinsmoor, 1927, P. 114)

Aunque la teoría podría ser pausible, no está documentada su intervención directa en los elementos de escultura arquitectónica que decoran el templo de Bassai. 


\section{Aproximación a la imagen clásica del friso}

Afortunadamente disponemos del ciclo narrativo completo del friso del Templo de Apolo en Bassai. Consta de 23 bloques de mármol y mide 31 metros de largo por 63 centímetros de alto.

Ictinos utilizó un friso jónico corrido en el interior de la naos - algo inédito en la época -, en un espacio oscuro, alto, con fuertes ángulos de visión, creando un conjunto totalmente innovador, donde las guerras de amazonas y centauros adquieren nuevos significados visuales, creando un nuevo concepto compositivo a través del claroscuro (Scully, 1969: 127).

Por todo ello, en el friso que adorna el interior del templo de Bassai la imagen clásica no está desprovista de aspectos expresionistas, y combina la crueldad y la rudeza arcaizantes con lo sutil y lo virtuoso. El artista griego o artistas que intervinieron en el templo fueron capaces de combinar conceptos convencionales y originales de una manera excepcional.

Cada imagen clásica tiene un origen expresivo, que hemos tratado de revitalizar en el desarrollo de nuestro proyecto. De aquí nace la propuesta de la "reincorporación", como interpretación y actualización, en la que las imágenes del friso asumen una nueva forma, permitiendo acercar el legado clásico al espectador moderno, y a las nuevas generaciones.

Aquello que hoy llamamos comúnmente clásico fue en su día moderno, innovador, y lo más importante, vivo. Lo que hoy llamamos convencional en la representación artística fue un lenguaje nuevo que sirvió a los pueblos griegos en un inicio, y a la cultura occidental posteriormente, para identificarnos como tales.

Las obras de arte son el resultado de muchas circunstancias, pero son, sin lugar a dudas, el fruto de un proceso creativo. Por este motivo en el estudio del proyecto utilizamos la práctica artística como una poderosa herramienta para abordar y analizar los principios del arte del pasado. Porque creemos que la poesía del arte en el presente nos permite conectar con la poesía del arte en el pasado de una manera muy especial, a la que no se puede llegar con el mero conocimiento intelectual del arte.

También pensamos que el arte no es sólo el producto de un estilo, sino que la obra de arte es un lugar de reunión del ser humano consigo mismo y, en ese sentido, no es solamente un objeto más o menos hermoso, sino de un lugar que nos sitúa fuera del tiempo. Y esta afirmación nos permite conectar desde el arte, momentos históricos distintos. De otro modo no reconoceríamos las emociones que transmiten las obras de arte del pasado, ni reconoceríamos nuestras emociones en ellas.

\section{Las interpretaciones de Bassai en la arquitectura británica ss. XIX-XX}

Bassai es un claro ejemplo de la cultura de la copia para la transmisión del legado clásico en el seno la cultura ilustrada. Más aún si tenemos en cuenta que la llegada de los mármoles del friso corresponde a un momento de revival griego. El Museo Británico produjo copias en yeso, una para cada uno de los participantes de la expedición, a cambio de la donación de la obra original al museo.

De acuerdo con los documentos del 14 de diciembre de 1816 (GM 1156 y C. 2644, Museu's Central Archive), el escultor Westmascott - autor neoclásico del 
frontón de la fachada del museo - fue encargado de la supervisión de dichas copias. No es de extrañar la expectativa creada por el friso que, junto a los mármoles del Partenón, también conocidos como Elgin Marbles, recientemente llegados a la metrópolis británica, crearon una suerte de "Nueva Arcadia" en el londinense barrio de Bloomsbury (Jenkins, 1992).

Los juegos de copias del friso fueron entregados en febrero de $1817 \mathrm{y}$, a partir de este momento, comenzó una nueva interrelación del friso de Bassai con la arquitectura contemporánea inglesa.

Thomas Legh emplazó una de las copias en su mansión de Lyme Park, en Cheshire, finca que actualmente forma parte del National Trust. El friso se presenta en un vasto corredor de tonos rojizo, donde se ubicó el friso a doble nivel, a modo de galería de yesos.

John Foster, otro de los expedicionarios, donó su copia del friso al Museo de Liverpool, su ciudad natal, quien la instaló en la Walker Gallery donde todavía hoy podemos contemplarla, tras su restauración en 1988 conformando parte de la gliptoteca.

Sin embargo fue el arquitecto Cockerell a quien mayor influencia causó el descubrimiento del friso y también quien a posteriori provocó con sus intervenciones una mayor influencia en la interpretación y difusión de la imagen del friso.

En primer lugar, adquirió la copia del friso perteneciente a Haller von Hallerstein, al morir prematuramente en 1818. Hizo donación de esta copia al Travellers Club de Londres, precisamente la sede de la Society of Dilettanti, de donde habían partido ocho años antes para su Grand Tour. En 1821 se instaló el friso en el comedor principal. Fue el mismo escultor Westmascott quien dirigió el trabajo de instalación del friso. Pero pocos años después, el club se trasladó a su actual sede, siempre en Pall Mall, en un edificio neoclásico diseñado por Charles Barry, quien proyectó la biblioteca del club con un espacio específico y las medidas adecuadas para contener el friso. Realizada bajo el gusto neoclásico, en su rectángulo total se establecen 3 espacios, que simulan los tres espacios del templo griego, esto es, pronaos, cella y opistodomos, siendo la cella el espacio donde encontramos el friso alla maniera de Bassai, aunque a menor altura.

Algunas de las características que observamos en esta adaptación de la réplica del friso en el Travellers' Club, se repiten en otras edificaciones en las que el propio Cockerell instala el friso, como veremos. El espacio arquitectónico reconstruido, en este caso por Barry se realiza bajo la forma ideal de un cuadrado. Si bien estos arquitectos sabían que la cella central era rectangular y, Cockerell especialmente, pues conocía el templo de propia mano, se opta por una 'forma ideal' en lugar de una 'forma real'. Podemos apreciar como las ideas preconcebidas del modelo clásico - alla Winckelmann - se imponen ante la propia visión in situ y los datos empíricos de los templos griegos como en el templo de Apolo Epikourios.

El segundo detalle es la ordenación (¿aleatoria?) de los bloques del friso. Como vemos si hacemos una comparativa entre estas instalaciones, el orden parece obedecer más a criterios 'decorativos' o de gusto personal que la búsqueda de una coherencia temática interna, a una sucesión temática, o a un criterio de fidelignidad con la disposición original del friso en el templo, tal y como correspondería a los objetivos 
de la actual arqueología.

Un tercer detalle es la aparición de fondos policromados, seguramente acorde con un gusto imperante en la época. El tema del color en la Grecia antigua era precisamente en estos momentos de la primera mitad del s. XIX-objeto de debate entre una imagen de una Grecia colorista y la 'Grecia blanca' de Winkelmann. Debemos tener en cuenta que en el friso aparecen trazas de policromía, y que actualmente han sido localizados restos de diversos colores. Más concretamente, el conocido 'azul egipcio' es el color más evidente, pues aparece en las trazas correspondientes al fondo del relieve original. Sin embargo, en el Travellers' Club, este rojo 'pompeyano' se ha mantenido como característico desde su actual colocación. En este sentido, siguiendo la sintonía cromática de Lyme Park.

Pero la influencia de Cockerell no quedó limitada a esta acción. En 1823 utilizó otra copia de Bassai para la residencia de verano de Robert Clive, miembro fundador del Travellers' Club, en Oakley Park, creando un espacio específico en la escalera, en lo que actualmente es un hotel de lujo. La mansión de Oackley Park pudo ser un primer ensayo para la posterior instalación en el Ashmolean Museum, pero aunque esto es sólo una hipótesis, constata la estrecha relación entre Cockerell y el friso, así como el sentido muy particular que el arquitecto tenía sobre la influencia del mundo clásico en sus obras. Nuevamente encontramos el friso instalado en un espacio cuadrado pero con iluminación cenital, tal como Cockerell concebía los templos griegos, como vemos en los grabados que realizó para su posterior publicación 'The Temples of Jupiter Panhellenius at Aegina, and of Apollo Epicurius at Bassae near Phigaleia, in Arcadia' (Cockerell, 1860).

Aunque sin duda, el uso más influyente de Bassai fue su ubicación en el nuevo edificio realizado por Cockerell para albergar el Museo Ashmolean de Oxford en 1845. El magnificente hueco de escalera donde el friso se enmarca recuerda el gusto de este momento y algunas de las convenciones neoclásicas de la lectura del arte griego (Fig.2).

El ejemplo de Oxford es muy significativo para entender cómo se realiza la recepción del friso en Cockerell. La construcción del edificio para el Ashmolean Museum, fue una respuesta neoclásica al movimiento neogótico en la ciudad universitaria de Oxford. Cockerell no podía olvidar un espacio significativo para la instalación de una de las copias del friso, y, como en el caso de Oackley Park, utilizó el plano superior del hueco de escalera. Es a causa de la construcción de este edificio cuando en 1837, veinte años después de la realización de primeras copias del friso, se reabre el interés por las piezas del friso de Bassai. El 23 mayo 1937 se registra una solicitud de un juego de copia para el Fritzwilliam Museum de Cambridge y el 23 febrero 1838, se menciona la adquisición de los Phigalian y de los Elgin Marbles por Basevi, suponemos que se refieren al mismo encargo ya que Basevi era el arquitecto del Fritzwillian (Central Archive, OP XVI, OP XVIII). También solicita una copia la Academia de Bellas Artes de Viena (OP XIX, 1 agosto de 1838).

Mientras en Oackley Park Cockerell utiliza unos chaflanes que crean una cierta sensación octogonal, en el Ashmolen encuentra una solución imaginativa incorporando unos tondi con cabezas que recuerdan las formas tanto de la estatuaria romana como del Renacimiento. Todo ello nos reafirma en la suposición de que Cockerell no tenía 
una clara opinión sobre cómo los bloques estaban dispuestos en su ubicación original en el templo, y que la presencia del friso era en su obra un constante revival de la Grecia clásica y de su propia experiencia del descubrimiento del templo de Apolo. Este hecho confirma que los criterios utilizados por Cockerell no corresponden a nuestro sentido contemporáneo de la arqueología.

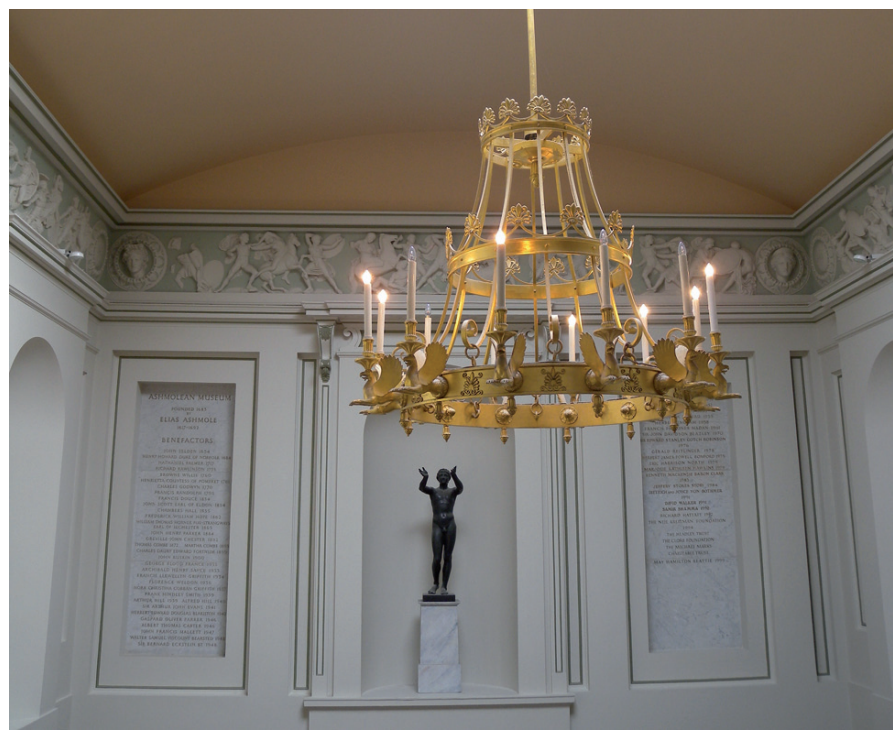

Figura 2. Hueco de escalera del Ashmolean Museum Projectado por Cockerell. Fotografía del autor.

Tanto en el Ashmolean y en Oackley Park, como en la versión del Travellers' Club, encontramos las tres características diferenciadoras de la lectura neoclásica del friso respecto del original. En primer lugar, la adaptación a un espacio cuadrado ideal que no corresponde con las dimensiones rectangulares del templo. En segundo lugar la diversa ordenación tanto de las escenas como de las esquinas en cada una de las adaptaciones de las copias en yeso. Y, finalmente la elección del factor cromático para el fondo. En el caso del Ashmolean, el color de fondo fue desde su inicio un azul oscuro, que asemejaba el 'azul egipcio' original del templo, Sin embargo actualmente podemos observar un gris verdoso, puramente por cuestiones estéticas en la ejecución de las recientes obras de remodelación del museo. Detalles como éste nos informan de la importancia que las cosas tienen en momentos históricos diversos. Para Cockerell el friso era un elemento destacado del hueco de escalera, mientras que para el arquitecto que ha realizado la remodelación, la intervención cromática da un aspecto neutro e incluso el friso puede pasar desapercibido para el visitante del museo.

Destacamos una última copia de Bassai correspondiente al Museo Fritzwillian de Cambridge, diseñado en 1835 por el también arquitecto neoclásico George Basevi, en la que Cockerell intervino. Indirectamente, ya que sólo se encargó de dirigir el final del edificio al haber quedado inacabado tras la desafortunada muerte de Basevi. No podemos explicar la relación que pudo llegar a tener con el espacio arquitectónico 
del Fritzwillian, ya que esta copia del friso se encuentra actualmente en el Museo de Arqueología Clásica de la Universidad de Cambridge, y corresponde a un segundo grupo de copias del friso de Bassai realizadas en esta ocasión por Brucciani, un formatore italiano que estableció en Londres la famosa casa de reproducciones Brucciani \& Co. Estos yesos, por tanto tienen un origen diverso, pero son de gran valor, ya que Domenico Brucciani fue uno de los más reconocidos creadores de copias en la segunda mitad del XIX, trabajando tanto para el Victoria \& Albert Museum (siguiendo su actual denominación) como para el Museo Británico, donde dirigió la sección de copias a partir de 1857.

Con el siglo XIX acabó el momento álgido de la influencia de Bassai. Del friso se hicieron algunas copias más, tanto dentro del ámbito Británico - desde Bristol se encargó una copia en 1923 (según consta en el Classical Art Reseach center. Beazley archive. No se precisa su localización actual.) -, como desde otras instituciones museísticas europeas y americanas. La relación con las réplicas de yeso de la escultura evolucionó conforme la sociedad y sus gustos estéticos se transformaban hacia el final de la época victoriana. El estudio y la admiración por los yesos fue decayendo a lo largo del s. XX como tónica general, mientras que el las últimas décadas - y primeras del s. XXI- una nueva valoración de los yesos está presente entre los estudiosos, y muchas colecciones y gliptotecas renuevan sus presentaciones, recobrando el prestigio perdido de esta copias.

El cambio de paradigma sufrido en el estudio de las Bellas Artes después de la Segunda Guerra Mundial es abrumador: en la segunda mitad del siglo las Academias y Escuelas de Bellas Artes abandonaron paulatinamente el aprendizaje basado en el estudio de los yesos, cuando antaño había sido ésta una de las prácticas centrales en las formación del artista.

Gracias a los estudios modernos sobre Bassai, desde el ámbito de la arqueología, y seguramente impulsado por haber obtenido por la UNESCO 1986 la calificación de primer monumento protegido de la Humanidad, tanto el conjunto del templo de Bassai como su friso han vuelto a ser objeto de análisis y no es extraño que esto haya llevado a la consideración de una nueva utilización de una réplica del friso de Bassai para una intervención arquitectónica.

Por ello destacamos el caso de la última adaptación de una copia de Bassai en un espacio moderno en el cual el friso ha adquirido una vital importancia. Se trata de la remodelación del Gonville and Caius College en Cambridge, de acceso prácticamente privado, que sirve a su vez como comedor para profesores. Proyectado en 1998 por el arquitecto inglés J. Simpson, parece una obra más inspirada en los grabados de Cockerell sobre el templo griego de Bassai (opus cit.,1860), que en el templo original.

Esta presentación de los moldes del friso de Bassai es una de las interpretaciones que mejor ha captado el sentido del espacio interior del templo. En la interpretación de Simpson, muchos elementos están alterados respecto al sentido arqueológico. Como por ejemplo, el uso de los colores, que nada tienen que ver con los originales. Ha mantenido el sentido polícromo del ambiente (friso, capiteles, etc.), pero modificado: lejos de encontrar los tonos vivos y brillantes y el contraste que tanto admiraban los griegos, aquí los colores son suaves y apastelados. Llama la atención también que el friso no se presenta como un friso jónico corrido, sino como un friso intercalado en los 
espacios delimitados por las columnas - seguramente por la necesidad de adaptación a una altura inferior de la sala con respecto a Bassai -. Tanto por la disposición de los elementos arquitectónicos del templo (columnas, capiteles...) como por la atmósfera de la nave, se aprecia la proximidad a los múltiples dibujos en los que al Cockerell ofrecía su particular visión de la arquitectura griega.

Así pues comprobamos que en los casos analizados las lecturas del friso se realizan mediante las adaptaciones más o menos deformadas del mismo al ámbito arquitectónico tanto en la esfera privada (mansiones) como en la pública (museos), enlazando con la cultura reproductiva europea de la transmisión del legado clásico a través de la copia.

\section{Interpretar la imagen clásica: una metodología experimental de la escultura a la fotografía}

Como para los viajeros del Gran Tour, en nuestro estudio la escultura es un elemento central del legado clásico. La teoría del arte se acerca al análisis de la imagen a través de conceptos artísticos que corresponden en gran medida a la forma plana y bidimensional de la pintura. Sin embargo queremos destacar en nuestro análisis cómo la escultura presenta varios aspectos que nos permiten obtener una perspectiva diferente sobre el proceso mismo de arte y, con ello, una perspectiva diferente de qué es lo clásico.

Destacamos especialmente: la importancia de los materiales en la obra, la necesidad del sentido del tacto (valores hápticos), la presencia física de la obra; la ocupación del espacio real; la relación integral entre la escultura y nuestro cuerpo como un todo; $y$, sobre todo, la manera dinámica de ver (a $\left.360^{\circ}\right)$ como forma óptima de captar la tridimensionalidad.

Estos aspectos se ofrecen en una doble perspectiva: en el proceso creativo de la producción de la escultura, que requiere una sensibilidad especial para el contacto directo con la materia prima; y en el disfrute del espectador, que dota de un vínculo especial con el objeto escultórico. Por ello la escultura requiere una formación más específica, una actitud activa e intensa, tanto en el aprendizaje teórico como en el práctico. Y requiere de un especial esfuerzo tanto para el artista como para el espectador: ahí radica su atracción, pero también el hecho de que para algunas personas la escultura sea algo distante y aparentemente inaccesible:

La escultura puede desarrollar nuestras habilidades de pensar tridimensionalmente e imaginar así como realizar formas tridimensionales. Estas habilidades tienen una gran importancia para la vida cotidiana que no está suficientemente reconocida en nuestras sociedades contemporáneas, que tienden a tratar este arte como un interés minoritario en que la mayoría no tiene que fijarse.[...] Es probable que, asi como los alfabetizados verbales conocen y entienden más del mundo y de la mente humana que los analfabetos, de igual manera los esculturalmente alfabetizados ven y entienden más del mundo tridimensional, a través de los modelos formales tridimensionales de la mente, que los esculturalmente analfabetos. (Rawson, 1997: 9) 
En esta manera particular de ver la realidad que la escultura nos ofrece, es importante la relación inseparable que existe entre la luz y la materia. La luz es un elemento esencial, especialmente en referencia a la sensación del espacio y de la forma tridimensional. En escultura, el modelado del volumen es una manera de crear el espacio necesario para que la luz pueda dibujar la silueta de la forma. Y esta piel de luz es su última capa, la superficie, aquello que percibimos. Como tal, la escultura también puede entenderse como un trabajo que se ocupa de la luz y de la relación de ésta con la materia. En nuestra investigación defendemos que hay un fuerte vínculo entre el efecto de la luz en la escultura y en la fotografía. Esta es la razón que nos lleva a trabajar en este y otros proyectos de revisitación de la escultura antigua con cámaras obscuras (camerae obscurae) como herramientas para entender la creación de una imagen. (Casanova, Egea, 2008).

Por tanto, cuando nos referimos a fotografía, lo hacemos como herramienta con un potencial para captar una forma gráfica, la fijación sobre una superficie dada y analizar con ello el arte del pasado. De esta manera, entendemos la fotografía en el sentido originario de photos graphein, de un dibujo realizado por la luz.

Este vínculo entre la escultura y la fotografía no es de ninguna manera artificial. Se basa en la idea central de dibujar con la luz (fotografía) o dibujar con la materia (escultura). Por lo tanto consideramos que la fotografía nos interroga sobre el significado de la visión, más allá de su uso instrumental, manteniendo una relación directa con el dibujo, como una forma de mirar el mundo.

Esta aproximación multidisciplinar facilita la confrontación de las tecnologías complementarias y permite una reflexión sobre el acto mismo de mirar. Y aquí nace la importancia del conocimiento de las artes para la creación de conocimiento. Por ello nuestra metodología de estudio ofrece un espacio, desde cualquiera que sea nuestro punto de vista, para preguntarnos qué miramos y cómo miramos, reflexionando sobre el enfoque a través del cual nos acercamos a ver, sobre la naturaleza de nuestra cámara externa o interna y, sobre todo, atendiendo a cómo la luz define la imagen en cualquiera de las distintas prácticas artísticas. Esta manera de entender cómo vemos a través del dibujo, a través del modelado o mediante la toma de fotografías es un concepto clave que tratamos de hacer realidad en nuestra manera de abordar un proyecto como el que nos ocupa, y que se resume en una filosofía de la práctica artística en la que la luz y la materia se funden en elementos esenciales para definir la configuración de la forma, permitiendo realizar análisis y diálogo con el arte del pasado.

Por eso usamos la fotografía como un acercamiento a la obra clásica, produciendo nuevas imágenes con la misma tecnología elemental utilizada por los pioneros de la fotografía. Esto establece un vínculo entre las técnicas empleadas y algunas de las imágenes creadas para nuestros proyectos, las imágenes que comparten el renacimiento del clasicismo en el s.XIX con los comienzos de una visión fotográfica del arte clásico.

Uno de los ejemplos pioneros de esta relación entre la escultura antigua y el arte incipiente de la fotografía es el Busto de Patroclo, de William Henry Fox Talbot, realizado en 1845. Esta imagen inicia una nueva forma de ver y estudiar el arte del pasado. 
También muchos escultores fueron capaces de entender la especial relación entre la luz y la materia, entre la fotografía y la escultura. Destacamos a Medardo Rosso (1858-1928), como uno de los casos más interesantes de este binomio fotografíaescultura, ya que fue un escultor innovador en muchos aspectos. Señalamos principalmente la atención que hizo a la luz en su obra escultórica.

Sus esculturas fueron realizadas en gran medida en cera sin fundir, como un material definitivo que permitía a Rosso que la luz bañara las piezas y crear con ello imágenes muy atractivas. Así queda remarcado en uno de los catálogos más completos sobre Rosso:

Medardo Rosso sostuvo un concepto de la escultura relacionado con la idea del instante suspendido y de aparición, que en última instancia, apuntaba a la inmaterialidad y a la intemporalidad. Esto implicaba la alianza con la materia circundante y una tendencia inevitable hacia su disolución en energía lumínica. Esto no quiere decir que negase la entidad materia de la escultural, sino, muy al contrario, que reconocía a la materia su cualidad de crisol de toda la forma, en lugar de servir a una especie de solidificación formal de la ficción. (Moure, 1997: i)

La idea de la captura del momento y de la luz llevaba a Rosso a utilizar la fotografía como una forma no sólo para reproducir sus obras, sino también para interpretar sus propias esculturas.

Si queremos aplicar estos principios al friso de Bassai, ¿como conseguimos amalgamar estas diferentes relaciones del arte: mirada, pasado, presente, escultura, imagen, fotografía...?

En primer lugar entendiendo que el arte, tanto en el pasado como en el presente, no es una mera combinación de las formas (líneas, colores y volúmenes) más o menos agradable a los sentidos, sino más bien como una acción que abre una puerta en el ser humano a un conocimiento sensible y profundo de la realidad. Remarcamos la capacidad del arte para interpretar sus propias imágenes, como es el caso de las imágenes del pasado clásico. Tal y como explica Eisner:

El trabajo de las artes no es sólo una manera de crear actuaciones y productos; es una manera de crear nuestras vidas ampliando nuestra conciencia, conformando nuestras actitudes, satisfaciendo nuestra búsqueda de significado, estableciendo contacto con los demás y compartiendo una cultura. (Eisner, 2004: 19)

Así como los artistas a lo largo del siglo XIX iban a los museos para hacer copias y los arqueólogos - estudiosos o dilettanti - de la época fueron a las excavaciones para descubrir el arte clásico, en el siglo XXI nuestro lugar arqueológico es el museo. En este caso, el Museo Británico, a mitad de camino entre una excavación, un taller y, en ocasiones un espacio donde crear un improvisado laboratorio fotográfico, permitió llevar a cabo experiencias técnicas que aúnan dibujo y fotografía de la escultura clásica, a la manera del XIX. 


\section{La reincorporación: una propuesta contemporánea de interpretación}

El concepto de reincorporación no es, desde luego, nuevo. Sin embargo lo remarcamos para diferenciarlo del de reintegración. Todas las actuaciones descritas del friso ha sido, de uno u otro modo, una reincorporación del mismo. Pero estas reincorporaciones estaban muy influenciadas por el propio concepto británico de restoration, es decir, una reintegración de manera más o menos fidedigna al original.

La historiografía a lo largo del siglo XX ha mostrado distintas vías de reincorporar el arte clásico, creando nuevas lecturas del mismo. Un caso paradigmático es el del alemán afincado en Inglaterra Aby Warburg (1866-1929), que ha sido uno de nuestras referencias paradigmáticas para afrontar este tipo de aproximaciones (Casanova, Egea, Rodríguez-Samaniego, 2012: 103-117). Su atención iconográfica configura una manera de reincorporar el mensaje del pathos clásico en el arte a lo largo de la historia, que él focaliza en el Renacimiento italiano.

El atlas de Mnemosyne, con su material iconográfico, quiere ilustrar este proceso que se podría describir como una tentativa de asimilar, a través de la representación del movimiento vivo, un fondo de valores expresivos preformados. Mnemosyne, como muestran las reproducciones del presente atlas, no quiere ser, de entrada, más que un inventario de las formas recibidas de la Antigüedad que han marcado el estilo de las obras del Renacimiento en su manera de representar el movimiento vivo. Semejante planteamiento comparativo debía [...] perseguir comprender, mediante una reflexión psico-psicológica más profunda, la función significativa que asumen en la técnica espiritual estos valores expresivos conservados por la memoria. (Didi-Hubermann, 2009: 431).

Esta reflexión está integrada en nuestra propuesta de reincorporación del friso de Bassai. Así como algunas propuestas de Wofflin, citado por Didi-Huberman, cuando refiere cómo los objetos se tornan imagen en el momento en que los vivimos (o nos viven) cuando afirma:

Las formas corporales no pueden tener carácter sino a partir del momento en que nosotros mismos tenemos un cuerpo. [...] Pero en tanto que hombres provistos de cuerpo que nos permite saber lo que es la pesadez, la convulsión, la fuerza, etc., acumulamos en nosotros mismos las experiencias que nos hacen capaces de compartir, de sentir el estado de las formas exteriores a nosotros [...] In voluntariamente, somos nosotros quienes animamos las cosas. Hay aquí una pulsión (trieb) ancestral de la humanidad. [...] Prestamos nuestra propia imagen a todos los fenómenos. (Didi-Hubermann, 2007: 69).

Otros artistas han presentado este concepto con una aproximación fotográfica, como Mimmo Iodice (Nápoles, 1934) en su estudio en el que las obras del Museo Archeologico de Nápoles adquieren una nueva vida o Adam Fuss (Inglaterra, 1965) quien también se ha aproximado al mundo antiguo con trabajos de camera obscura.

Hans Belting, afirma que el misterio de la imagen no está en la forma, sino en su 
formación, que es su reincorporación. Nos introduce al hecho de que las imágenes no son objetos que podamos poseer, no son elementos bidimensionales sobre la pared o sobre el papel de un libro. Mucho más allá, nosotros somos el lugar de las imágenes, el lugar donde las imágenes ocurren, donde las imágenes se encarnan, se reincorporan:

Desde la perspectiva antropológica, el ser humano no aparece como amo de sus imágenes, sino -algo completamente distinto-como <lugar de las imágenes $>$ que toman posesión de su cuerpo: está a merced de las imágenes autoengendradas, aún cuando siempre intente dominarlas. (Belting, 2007: 14)

Para aplicar nuestras ideas al caso de Bassai, el museo de Cambridge nos ofreció la posibilidad de crear un paralelismo entre el friso en yeso y un nuevo friso creado con las imágenes del proyecto, por lo que se configuraron una serie de relaciones reales entre lo clásico y lo contemporáneo, que recordaban aspectos originales del friso, como la atención al color, la expresividad de sus figuras, la intención de la composición, etc.

Esta reincorporación ha sido una aproximación potenciada por la capacidad de las bellas artes para que las imágenes tomen nuevo cuerpo. Mientras en el XIX se buscaba una objetividad positivista en la representación, en el s. XXI somos conscientes de que nuestra mirada no profundiza en la objetividad de la lectura sino, todo lo contrario, en su capacidad interpretativa, hermenéutica. Las aproximaciones de los integrantes de este proyecto han considerado nuevas relaciones con lo clásico desde sus posicionamientos contemporáneos, interpretando de manera diversa y complementaria el friso de Bassai.

El positivismo del XIX ayudó al triunfo de la fotografía. Pero la fotografía estableció, inevitablemente, un lenguaje autónomo que se alejó de una concepción maquinal y objetiva. Los fotógrafos y los artistas fueron incapaces de crear imágenes verdaderamente objetivas de las ruinas arqueológicas, y esto ha llevado al establecimiento de un estilo propio, con una estética que denominamos decimonónico.

Siguiendo estos principios, Israel Ariño y Rebecca Muttell han utilizado el colodión húmedo, técnica fotográfica más usada en las excavaciones de segunda mitad del siglo XIX, desde que en 1851 Frederick Scott Archer la diera a conocer, hasta la irrupción de las placas secas de gelatino-bromuro en la década de los 80 del mismo siglo (fig. 3). Si bien es evidente que la fotografía no fue utilizada en las excavaciones de Bassai en 1811-12, con esta técnica se realizaron muchas de las imágenes que se practicaron en las excavaciones arqueológicas de la segunda mitad del siglo XIX y sugiere la licencia poética de cómo hubieran sido unas imágenes del friso realizadas en la Arcadia. 


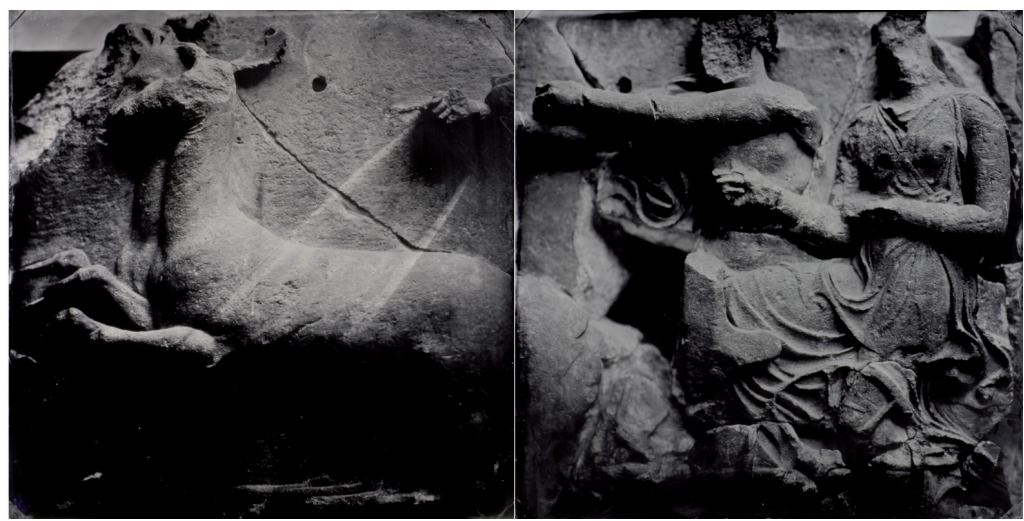

Figura 3. Ariño-Mutell, El Carro de Apolo. Colodión Húmedo sobre aluminio Fotografía: cortesía de los artistas.

Las particularidades de la técnica y sus necesidades logísticas nos hicieron sentir como expedicionarios, y de algún modo aproximarnos al friso como los ocho expedicionarios lo hicieron con sus hallazgos. Para obtener un colodión, la sensibilización de la placa y su revelado deben realizarse en un breve período de tiempo, manteniendo el colodión húmedo durante todo el proceso. La emulsión se preparó sobre placas metálicas que generan originales únicos, positivos directos, con la necesaria imagen invertida derecha-izquierda. Una de las cualidades del ferrotipo es su carácter objetual, recordando una imagen traída del pasado, lo cual sugiere el hipotético viaje al siglo XIX.

Como contrapunto tecnológico, José Luis Eguía y Ruth Contreras, investigadores de la UPC y de la UVic respectivamente, crearon una aplicación Ipad en la cual, sobre la base de la narrativa del friso, se superponen y despliegan las formalizaciones derivadas del proyecto, generando una síntesis del mismo. El interactivo facilita la interrelación y el diálogo entre las diferentes lecturas gracias a lo cual el usuario del aplicativo construye una idea propia sobre el friso. La aplicación permite acceder al friso sin necesidad de acudir al Museo, y supone una revolución similar a la que en su momento constituyó el traslado del hallazgo desde Bassai hacia el Museo Británico.

Movidos por la particular orientación norte-sur del templo, se estableció la hipótesis de que las escenas del friso, situadas en lo alto de la naos cobraban vida, bien por el crepitar de luminarias situadas contra-cenitalmente o bien, y sobretodo, por la expansión de la abrumadora luz que entraba en el ádyton a través la apertura practicada en dirección este.

El templo recogía la luz de la mañana, la energía del sol en su momento germinal, y la otorgaba al espacio uterino de la naos. Este efecto, que da entidad a la advocación del templo a Apolo, dios solar, debía ser especialmente intenso en los equinoccios, cuando el sol nacía exactamente al Este. Con el objetivo de explorar el simbolismo de esta relación lumínica, incidiendo en la fuerte coloración de la iluminación de la mañana, y aprovechando el carácter expansivo del rojo y los violáceos, Ramón Casanova trabajó en unas imágenes que emulan el proceso publicado en 1869 por Ducos du Hauron. Usó como negativo papel cromogénico, utilizado normalmente 
para la realización de ampliaciones en laboratorio. Para corregir su dominante se necesitó realizar tres tiempos de exposición, uno con cada color primario, aunque el tiempo necesario para equilibrar las tres exposiciones en una sola imagen era variable, y todo el proceso precisó también del laboratorio in situ (fig. 4).

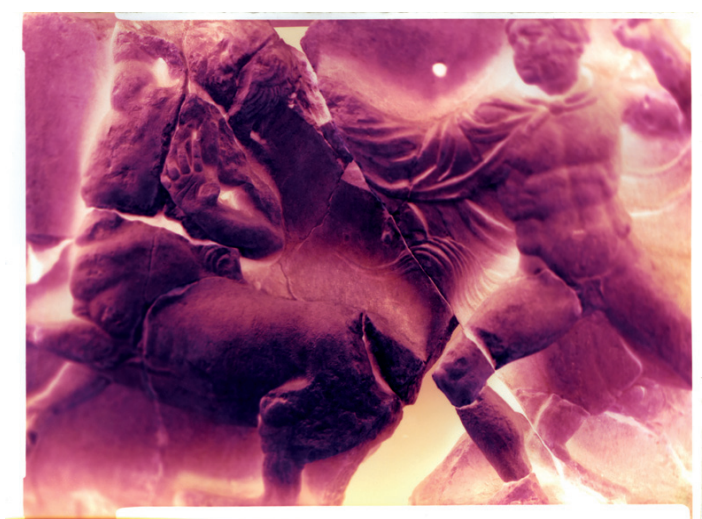

Figura 4. Casanova, Griego luchando contra un centauro. Negativo cromogénico.Fotografía: cortesía del artista.

Las imágenes finales se mantienen en negativo, lo cual invierte la relación habitual de luces y sombras, ya que los negros en la imagen eran luz en la escena, por lo que sumando el uso de una iluminación contra-cenital se generó una falsa percepción de realidad.

En el trabajo de Carles Bartolomé-Ibars podemos ver como la forma emerge de la sombra, generando volúmenes superponiendo niveles de luminosidad sobre una base penumbrosa. Las formas se desvanecen en una amalgama de relaciones entre luz y sombra. Esto potencia la idea simbólica de la forma siendo creada por la luz. En esta ocasión la reincorporación, es una propuesta iconográfica contemporánea del friso, tanto un dibujo realizado a grafito sobre papel como en la versión final pintada al óleo, ambos de 440x160 cm. (fig.5). En esta propuesta se ha generado una relación entre el trabajo de campo, centrado en la captación y el desgrane de la forma en estímulos visuales après nature y la interiorización y actualización de resultados realizados posteriormente en el estudio a partir de este material primario.

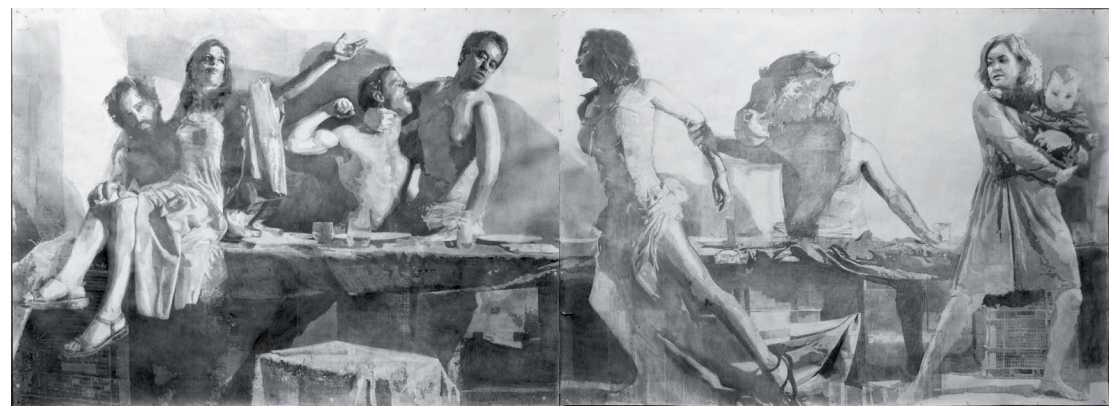

Figura 5. . Carles Bartolomé-Ibars, Re-incorporación del Friso de Apolo, 2011. Lápiz de grafito sobre papel. Fotografía: cortesía del artista. 
Otros miembros del equipo de investigación realizaron propuestas en paralelo a estos resultados que hemos destacado. Por ejemplo, Mónica Lou consiguió una serie de imágenes realizadas con una cámara de medio formato, que nos permiten aproximarnos y descubrir carne donde antes sólo había piedra. Aislando y ampliando detalles, percibimos gestos de las figuras, percibimos huellas del trabajo del escultor. Adivinamos el todo a partir de la parte, y pre-configuramos estructuras y ritmos subyacentes y también, su aspecto carnal.

Mientras, Enric Passolas trabajando desde la tradición naturalista y científica, generó una serie de dibujos luminosos, analíticos, exactos, que nos muestran la versión más apolínea del friso. Aquí los personajes se enajenan de la narrativa del friso, de la línea temporal, del dramatismo. Propiciando una aproximación de iconográfica clásica, que no cae en el formalismo académico, sino en la libertad que ofrece la maestría del oficio. A su vez, Adrián Arnau hizo unos bocetos que, transformados posteriormente en dibujos de lápiz de plata sobre cartón debidamente imprimado, ponen en evidencia la fuerza compositiva del friso y su elaboración dinámica basada en diagonales.

El análisis formal del friso se completa con el estudio de ritmos y simetrías que ha desembocado en uno de los hallazgos más innovadores del proyecto: la hipótesis del uso de plantillas o patrones que, repetidos con pequeñas variaciones, invertidas y entrecruzadas, permitieron al escultor que diseñó el friso otorgar al mismo armonía y musicalidad, siguiendo el sentido monódico de la música, danza y, sobre todo, de la poesía griega. El friso está compuesto del mismo modo que un poema épico, y es en esta tipología de poesía en la cual encontramos una mayor testimonianza del uso ejemplar del hexámetro. La utilización de plantillas era habitual en la cerámica roja y en otros ámbitos artísticos, y también es compartido por la escultura. Especialmente en el relieve, para traspasar el dibujo sobre la piedra, la plantilla es una herramienta ágil con la que mantener proporciones y equilibrio en el conjunto.

\section{Conclusiones}

El solapamiento de lecturas permite profundizar la mirada en torno al friso de Bassai, ejemplo de fascinante conjunción entre formas arcaizantes y soluciones vanguardistas. Ésta es una de las ventajas de la investigación en equipo, que favorece sinergias y entrecruzamientos en el objetivo de perseguir visualizaciones o intuiciones particulares, abriendo un posible camino para la investigación en las bellas artes.

Por tanto, investigar a través del arte es fomentar la capacidad del arte para explicarse a sí mismo, la posibilidad de establecer a través del arte correspondencias y sincronicidades trascendiendo las etiquetas que lo separa en clases o momentos históricos. Como señala Calvino clásico no es necesariamente un modelo inamovible, sino el modelo que permanece a través del tiempo porque cada generación es capaz de adaptar su discurso e incorporarlo (Calvino, 1981). 


\section{Referencias}

Baker, M. (2000) La Consommation de l'Antique: le Grand Tour et les reproductions de sculpture classique. En Gaborit, J. R, Pasquier, A. (eds.) D'après l'Antique. Paris: Musée du Louvre, pp.33-41.

Beard, M. \& Henderson, J. (1995) Classics: A Very Short Introduction. Oxford: Oxford University Press.

Belting, H., (2007) Antropología de la imagen. Madrid: Katz ed.

Calvino, I. (1981) Italiani, vi esorto ai classici. En: L’Expresso, Milán, 28/06/1981.

Cardete, M. C. (2010) La Antigüedad y sus Mitos. Narrativas Históricas Irreverente. Madrid: Siglo XXI.

Casanova, R. \& Egea, J. (2008) Dopo il Museo. Re-creazione Museo Archeologico di Napoli. Barcelona: Biblioteques de Barcelona.

Casanova, R., Egea, J. \& Rodrigues-Samaniego, C. (2012) Mnemosyne y el proyecto Trans-formare, lecturas de la transformación del museo Frederic Marès de Barcelona. En Arte, Individuo y Sociedad 24(1); http://dx.doi.org/10.5209/ rev ARIS.2012.v24.n1.38046

Dinsmoor, A. S. (1927) The Architecture of Ancient Greece. London: Harrison, Jehring and Co.

Didi-Hubermann, G. (2007) La imagen mariposa. Barcelona: Mudito\&Co.

- (2009). La imagen superviviente. Historia del arte y del tiempo de los

fantasmas según Aby Warburg. Madrid: Abada.

Eisner, E. W. (2004) El arte y la creación de la mente. Barcelona: Paidós.

Jenkins, I. (1992) Archaeologists and Aesthetes: In the Sculpture Galleries of the British Museum 1800 - 1939. London: British Museum Press.

Moure, G. (1997) Medardo Rosso. Barcelona: Polígrafa.

Rawson, Ph. (1997) Sculpture. Philadelphia: University of Pennsylvania Press.

Scully, V. (1969) The Earth, the Temple and the Gods: Greek Sacred Architecture.

New York: Frederick A. Praeger, Inv. Publisher.

Osborne, R. (1998). Archaic and classical Greek Art. Oxford: Oxford University

Press. 